\title{
NOWE WERSJE ZASADY KOSMOLOGICZNEJ A KWESTIA NIEROZSTRZYGALNOŚCI PYTANIA O POCZĄTEK CZASOWY WSZECHŚWIATA
}

W przedstawionym przez E. Kanta ${ }^{1}$ ujęciu problemu początku czasowego wszechświata udowadniana była zarówno teza o absolutnym początku czasu, jak i o jego odwiecznym istnieniu. Rozwiązanie przedstawione w niniejszym artykule jest przeciwne w stosunku do Kantowskiej koncepcji i wykazuje się w nim, iż zasadniczo niemożliwe jest wypracowanie argumentu czy to za finistyczną, czy też infinistyczną interpretacją przeszłości wszechświata.

Sytuacja taka uwarunkowana jest tym, iż rozwiązując problem początku należy przyjąć pewne fundamentalne i najbardziej ogólne założenia odnoszące się do wszechświata jako całości. Zależnie od przyjętej wersji zasady kosmologicznej czy definicji wszechświata może się okazać, iż stan uważany za absolutnie pierwszy $\mathrm{w}$ określonym systemie $\mathrm{S}_{1}$, będzie stanem względnie pierwszym w ramach systemu $\mathrm{S}_{2}$.

W prezentowanym ujęciu nie usiłuje się zacierać różnicy między modelami wszechświata z absolutnym początkiem czasowym a koncepcja wszechświata istniejącego odwiecznie. Uznając istnienie podobnych różnic wykazuje się tylko, iż rozwiązanie zagadnienia absolutnego początku czasowego (rsp. wieczności wszechświata) uzależnione jest od założeń, jakie poszczególni autorzy 'wprowadzają w przyjmowanej - przynajmniej implicite — zasadzie kosmologicznej ${ }^{2}$.

1 E. Kant, Krytyka czystego rozumu, Warszawa 1957, t. 2, 164-174.

2 W dalszych analizach wyrażenia ,nowa zasada kosmologiczna” i ,nieortodoksyjna zasada kosmologiczna" używane są synonimicznie w odniesieniu do wariantów zasady różnych zarówno od klasycznej zasady kosmologicznej zwanej zwykłą czy tradycyjną, jak i idealnej zasady kosmologicznej sformułowane przez twórców teorii stanu stałego. 
1. WSPÓECZESNE PROBY SFORMUŁOWANIA NIEORTODOKSYJNYCH ZASAD KOSMOLOGICZNYCH

Empiryczna falsyfikacja idalnej zasady kosmologicznej, sformułowanej przez H. Bondiego, F. Golda i F. Hoyle'a w 1948 r., przyczyniła się do wzrostu krytycyzmu także w stosunku do zwykłej zasady kosmologicznej, w jakiej przyjmuje się statystyczną równoważność wybranych dowolnie odpowiednio wielkich obszarów jednorodnego i izotropowego wszechświata, w którym prawa fizyki i pewne wielkości zwane stałymi nie zależą od pozycji obserwatora ${ }^{3}$. Wprawdzie jeszcze $\mathrm{w}$ latach sześćdziesiątych Bondi podkreślał, że we wszystkich teoriach kosmologicznych przyjmuje się tę podstawową zasadę i wśród kosmologów panuje powszechna zgoda co do konieczności jej akceptacji; dyskusje miały dotyczyć jedynie eksplikacji treściowej, statusu epistemologicznego czy kwestii granic ekstrapolacji zasady ${ }^{4}$. Nie przesądzało to jednak w niczym zagadnienia, czy powszechna akceptacja nie jest jedynie oznaką wstępnego tylko i najprostszego z możliwych rozwiązań problemu struktury wszechświata. Bondi przyznawał zresztą obiektywnie, że zasada kosmologiczna nie jest wystarczająco uzasadnionym twierdzeniem, lecz postulatem, który wprowadza się do teorii fizykalnych, by uprościć naukowe studium wszechświata ${ }^{5}$.

1. W coraz częstszych próbach kwestionowania tradycyjnej zasady kosmologicznej, podejmowanych zarówno z empirycznego jak i teoretycznego punktu widzenia, zwraca się uwagę, że w latach dwudziestych naszego stulecia usiłowano traktować jako ,,jednorodne w przybliżeniu" skupiska materii, które dziś uważa się za typowo niejednorodne. Klauzule o ,przybliżonej” jednorodności czy o spełnianiu zasady w ,dostatecznie wielkich obszarach" niewiele tłumaczą, gdyż otwartym pozostaje problem, jakie obszary $\mathrm{w}$ praktyce należy traktować jako dostatecznie wielkie. Brak precyzyjnych określeń sprawia, że gdyby wykazano obserwacyjnie np. niejednorodny rozkład materii w określonych rejonach wszechświata, zwolennicy tradycyjnej zasady kosmologicznej mogą nigdy nie uznawać jej falsyfikacji, twierdząc, iż należy uwzględnić jeszcze większe obszary. Interesujący i znamienny jest fakt, że z rozwojem kosmologii ustawicznie zwiększają się oszacowania dolnej granicy obszarów, jakie można by uznać za jednorodne.

W płaszczyźnie analiz teoretycznych wyrażane są wątpliwości co do prawomocności absolutnej, nieograniczonej ekstrapolacji na wszystkie rejony wszechświata prawidłowości fizykalnych potwierdzonych empi-

3 Różne wersje klasycznej zasady kosmologicznej zob. M. Heller, K. Rudnicki, Ewolucja zasady kosmologicznej, ,Analecta Crac.”, 4 (1972) 33-49.

4 Kosmologia, Warszawa 1965, 21.

5 Tamże, 22. 
rycznie jedynie dla pewnego obszaru. Jakkolwiek z zasady twierdzenia przyrodoznawstwa mają charakter prognostyczny a ekstrapolacji nie można w nich zastępować przez indukcję zupełną, to jednak nie wynika z tego możliwość bezgranicznej ekstrapolacji jakichkolwiek praw. Z tego, że prawa klasycznej mechaniki można ekstrapolować na poziomie makrokosmicznym nie można wnioskować o ich obowiązywalności na poziomie mikrokosmosu. Ekstrapolację w niektórych przypadkach stosuje się z racji metodologicznych czy heurytycznych, a nie doktrynalnych. W konsekwencji także i przyjmowane w celach heurystycznych postulaty o jednorodności i izotropowości wszechświata mogą okazać się słuszne w odniesieniu do określonego układu obiektów materialnych, a nie można ich ekstrapolować poza granice tego układu. Założenie izotropowośc: wszechświata odrzucone zostało już w słynnym modelu Goedla z 1949 r. Wprawdzie zarówno względy praktyczne (niemożliwość rozwiązania równań poniżej pewnych symetrii) jak i stosunkowo zadowalajacy opis procesu przez modele Friedmanowskie skłaniają kosmologów do przyjęcia tradycyjnej zasady kosmologicznej, już jednak sam A. A. Friedman uwzględniał możliwość, iż model jego skutkiem idealizacji może zniekształeać rzeczywistość ${ }^{6}$.

2. Rozwój analiz kosmologicznych w latach sześćđziesiątych, próby traktowania obserwowanego wszechświata jako elementu składowego wszechświata wyższego rzędu oraz badania autorów kierujących się założeniem, iż ,adekwatność modelu Friedmana do opisu aktualnego stanu wszechświata nie daje podstaw, by oczekiwać, że jest on także przydatny do opisu wezesnych stadiów ewolucji" 7 doprowadziły do rozwoju koncepaji, w których uwzględnia się większą różnorodność procesów, warunków i współoddziaływań niż w tradycyjnych rozwiązaniach kosmologicznych. W pracach zainicjowanych przez A. L. Zelmanowa ${ }^{8}$ i K. P. Stanjukowicza ${ }^{9}$ przyjęto jako podstawową zasadę metodologiczną twierdzenie, iż w różnych obszarach wszechświata realizowana jest cała różnorodność zjawisk i wzajemnie niesprzecznych warunków. W innych ukladach materii występować mogą inne prawa rozwoju, inne ,stałe”, odmienne zapasy energii czy rozmiary cząstek.

W analizach L. E. Gurewicza ${ }^{10}$ stanowiących rozwinięcie zasadni-

6 Por. A. Tursunow, Naprawlenije wremieni: nowyje aspiekty staroj problemy, ,Wopr. Fił.”, (1975, 3) 60.

7 L. D. Landau, E. M. Lifszic, Tieorija pola, Moskwa $1973^{6}, 449$.

8 Zob. np. A. L. Zelmanow, $K$ postanowkie kosmołogiczeskoj problemy. Dopotnienije, w: Trudy II sjezda Wsjesojuznogo astronomogieodieziczeskogo obszczestwa, Moskwa 1960; Mietagałaktika $i$ Wsielennaja, w: Nauka i czełowieczestwo, Moskwa 1962; Kosmołogija, w: Fiziczeskij encikłopediczeskij słowar', t. 2, Moskwa 1962.

9 Problemy tieorii grawitacji $i$ elemientarnych czastic, Moskwa 1966, 272.

$10 \mathrm{Ob}$ odnoj fundamientalnoj problemie w kosmołogii, w: Ewristiczeskaja rol' matematiki w fizikie i kosmologii, Leningrad 1975, 39-57. 
czych idei Zelmanowa podstawowa zasada ma charakter opozycyjny w stosunku do ortodoksyjnych sformułowań zasady kosmologicznej i orzeka, iż w poszczególnych układach kosmicznych realizuje się wszystko, cokolwiek jest możliwe (niesprzeczne wewnętrznie). Układy typu naszego Wszechświata istnieją obok nieskończonej ilości innych układów tego rzędu w superprzestrzeni, której zadowalająca charakterystyka jest niemożliwa w terminach współczesnej fizyki 11. Poszczególne układy -wbrew tradycyjnej zasadzie kosmologicznej - różnią się gęstością materii, ilością wymiarów przestrzeni ${ }^{\mathbf{1 2}}$, znakiem krzywizny przestrzeni ${ }^{13}$, występującymi prawidłowościami rozwoju. Gurewicz przyjmuje, iż im bardziej proste jest jakieś prawo fizyki, tym w większej ilości układów obowiązuje ono; bardziej skomplikowane prawidłowości zachodzą w relatywnie mniejszej ilości systemów. Nie określa on jednak, jakie ponadsystemowe kryterium prostoty praw można by przyjąć w tym przypadku, ani też nie usiłuje uzasadniać tezy o ujemnej korelacji między złożonością praw a częstością ich występowania. Rozwiązanie takie może więc razić swoją dowolnością; może też być uważane za przejaw fantazji. Niemniej analogiczne zarzuty wysuwane były w historii nauki nierzadko pod adresem koncepcji, jakich obecnie nie kwestionuje się.

W ujęciu Gurewicza można by krytykować pewne konkretne, drugorzędne dla istoty zagadnieenia wnioski. Kiedy np. usiłuje on wykazywaé przez odwołanie do równań Ehrenfesta ${ }^{14}$, iż życie nie może istnieć $\mathrm{w}$ układach o liczbie wymiarów $\mathrm{n}>3$, to wbrew pierwotnemu zalożeniu ${ }^{15}$ twierdzi on, że we wszystkich układach zewnętrznych muszą byó spełnione równania Ehrenfesta, oraz nie zauważa iż w nieskończonej różnorodności zjawisk mogą także występować formy życia różne od istniejących na Ziemi.

Sygnalizæwane braki nie przesądzają jednak niczego odnośnie wartości nowych sformułowań zasady kosmologicznej. Przy ocenie wartości tej zasady zauważyć należy natomiast jej heurystyczną płodność. Odejście od ortodoksyjnych wersji zasady umożliwiło m. in. podjęcie prób nowego rozwiązania problemu kosmologicznej osobliwości początkowej ${ }^{16}$.

11 Tamże, 50.

12 Koncepcja superprzestrzeni u Gurewicza, mimo zbieżności terminologicznej. jest treściowo zupełnie obca koncepcji superprzestrzeni u J. A. Wheelera. W ujęciu radzieckiego fizyka: „swierchprostranstwo [...] nie możet byt' charaktierizowano opriedelennoj gieometriej i opriedelennym czisłom izmierienij [...], jego możno otożdiestwit' so swobodnym grawitacjonnym polem ili, tocznieje, s tiem, czto sootwietstwujet niekotorym jego obobszczenijom". Tamże, 54.

13 Tamże, 44, 46.

14 P. Ehrenfest, In what way does it become manifest in the fundamental laws of physics that space has three dimensions?, „Proc. Amst. Acad.”, (1917) 20.

15 Gurewicz, art. cyt., 44.

16 Zob. np. D. I. Błochincew, O gipotezie rasszirjajuszczejsja Wselennoj, „DAN SSSR", 229 (1976) 67-69. 
2. PROBLEM POCZĄTKU CZASOWEGO W MODELACH Z NIEORTODOKSYJNA ZASADA KOSMOLOGICZNA

W ujęciu A. L. Zelmanowa konsekwencją odejścia od ortodoksyjnej wersji zasady kosmologicznej jest rozróżnienie między wszechświatem w całości, całym wszechświatem a wszechświatem jako całością. Pierwsze z tych pojęć oznacza całość niezależną od części, drugie wszystkie części niezależnie od całości, trzecie - całość w stosunku do części składowych. W wyniku wprowadzonego rozróżnienia wszechświatowi jako całości nie można przypisywać pewnych cech charakterystyeznych dla poszczególnych układów materii, ponieważ własności te moga posiadać jedynie lokalny charakter.

Konsekwencje wprowadzonych dystynkcji są doniosłe dla filozofii przyrody, ponieważ prowadzą one do oryginalnych definicji wszechświata i ukazują nowe możliwości postawienia problemu początku materii.

1. Definicje wszechświata przyjmowane - przynajmniej implicite w dotychczasowych teoriach kosmologicznych można podzielić pod względem treści na dwie zasadnicze grupy. W ujęciu pewnych autorów, którzy stosunkowo liberalnie traktują postulat emiprycznej sensowności terminów, pod pojęciem wszechświata rozumie się zbiór wszystkich istniejących obiektów materialnych. W drugim z sygnalizowanych ujęć termin „wszechświat" denotuje zbiór galaktyk tworzący jednolity system dostępny do poznania fizykalnego, który to system może ewentualnie okazać się częścią składową wszechświata wyższego rzędu.

Definicje pierwszego typu znaleźć można np. w rozwiązaniach $\mathrm{F}$. Hoyle'a i C. K. Granta, gdy określają oni wszechświat jako „zbiór wszystkich rzeczy" 17 lub ,wszystkich zdarzeń fizycznych" 18 czy u M. Scrivena ${ }^{19}$ i H. Reichenbacha ${ }^{20}$, kiedy stwierdzają oni, iż wszystko, co istnieje stanowi wszechświat. Niektóre z tych sformułowań pozbawione dopowiedzeń relatywizujących czy kwantyfikujących mogą łatwo prowadzić do nieporozumień, ze względu na wieloznaczność terminów „rzecz” i ,istnienie". Również niektóre określenia drugiej grupy pozbawione sa precyzji. Obok ostrej definicji podánej przez M. Hellera ${ }^{21}$, który pod pojęciem wszechświata rozumie największy zbiór wszystkich zdarzeń, z jakimi możliwy jest kontakt fizyczny przez recepcję i wysyłanie sy-

\footnotetext{
17 F. H o y le, Frontiers of Astronomy, New York 1963, 270.

18 C. K. Grant, Some Comments on the „Age of the Universe”, „Brit. J. Phil of Sc.", 6 (1955) 249.

19 The Age of the Universe, „Brit. J. Phil. of Sc.”, 5 (1954) 186.

20 Powstanie filozofii naukowej, Warszawa 1960, 213.

21 Definicja terminu wszechświat w kosmologii relatywistycznej, „Rocz. Fil.”, $164(1968,3)$ 58. Zob. też M. Heller, M. Reinhardt, Meaningless Questions in Cosmology and Relativistic Astrophysics, „Z. Naturforsch.”, 31 a (1976) 1273.
} 
gnałów przekazujących informacje, spotyka się mniej precyzyjne sformułowania, w jakich terminy „wszechświat", ,świat”, „Metagalaktyka” czy „Teragalaktyka” są używane zamiennie. W ujęciach tych termin definiowany denotuje bądź to zbiór obiektów, do których można stosować znane prawa fizyki, bądź też największy zbiór obiektów, które są zasadniczo dostępne do obserwacji w pewnych stadiach ewolucji układu.

W drugiej grupie rozwiązań nie nadaje się więc terminowi „wszechświat" absolutnego znaczenia i nie uważa za jego denotację zbioru wszystkich istniejących obiektów materialnych, lecz relatywizuje się koncepcję wszechświata do aktualnego stanu wiedzy czy możliwości kontaktu fizycznego. Jeśli na gruncie tego ujęcia zrezygnuje się $\mathrm{z}$ tradycyjnej zasady kosmologicznej, nie można wykluczyć możliwości, iż wszechświat $\mathrm{w}$ jakim żyjemy jest jedynie jednym z nieskończonej ilości układów opisywanych przez Gurewicza ${ }^{22}$. Próbę bliższej charakterystyki układów tego typu podjął $\mathrm{m}$. in. D. I. Błochincew ${ }^{23}$. W jego ujęciu w płaskiej pseudoeuklidesowej metaprzestrzeni $M_{n}(x)$ z ilością wymiarów przestrzennych $\mathrm{m}>3$ i jednym wymiarem czasowym zanurzone są układy i antyukłady niższego rzędu. W metaprzestrzeni tej, gdzie interwał $\mathrm{d}$ s określony jest wzorem $\mathrm{ds}^{2}=\mathrm{dx}_{0}^{2}-\sum_{\mathrm{k}=1}^{\mathrm{m}} \mathrm{dx}_{\mathrm{k}}^{2}$ rozpatrywana jest hiperpowierzchnia $\mathrm{x} \mu=\mathrm{F} \mu\left(\xi_{0}, \xi_{1}, \xi_{2}, \xi_{3}\right)$ o interwale długości $\mathrm{d} \sigma^{2}=$ $=\operatorname{g} \alpha \beta \mathrm{d} \xi \alpha \mathrm{d} \xi \beta$. Koncentrując uwagę tylko na pewnych typach hiperpowierzchni $\mathrm{z} \mathrm{g}_{00}>0$ i det $\mathrm{g} \alpha \beta<0$ oraz nadając fizyczną interpretację wyodrębnionej klasie hyperpowierzchni Błochincew ukazuje nowe możliwości rozwiązania problemu początku naszego wszechświata, który byłby $\mathrm{w}$ tym ujęciu analogatem hyperpowierzchni $R_{4}(\xi)$ zanurzonej $\mathrm{w}$ metaprzestrzeni $\mathrm{M}_{\mathrm{n}}$ (x). W rozwiązaniu tym stan kosmologicznej osobliwości początkowej był rezultatem zderzenia się dwóch lub większej ilości układów typu naszego wszechświata. A priori dopuszczana jest także możliwość zderzeń $\mathrm{z}$ innymi układami tego typu w późniejszych stadiach rozwoju. Błochincew nie podejmuje dokładniejszej charakterystyki metaukładów, uznając zagadnienie za otwarte dla spekulatywnych rozwiązań ${ }^{24}$.

Próbę opisu „kontaktowego spotkania” ewoluujących niezależnie metaukładów podejmuje także Gurewicz. I on pozostawia jednak także nierozwiązanym problem konsekwencji „spotkania” metaukładów o różnej ilości wymiarów przestrzeni czy o różnych topologiach ${ }^{25}$. Kancepcję tę

2 Art. cyt.

23 Art. cyt.

24 „Boleje dietalno opriedielit' prirodu etich mietatieł byłoby prieżdiewremienno. Poka zdies' ostajetsja bolszaja swoboda dla spekulacji. Eto mogli by byt' elemientarnyje czasticy obładajuszczije ogromnoj energiej". Tamże, 69.

25 Art. cyt., 50. 
podjęli także R. A. Asanow, W. R. Frołow, M. A. Markow ${ }^{26}$, P. K. Kobuszkin ${ }^{27} \mathrm{i}$ in. Dopuszczają oni istnienie nowych hipotetycznych cząstek nazywanych friedmonami ${ }^{28}$, maksymonami ${ }^{29}$, fundamentonami ${ }^{30}$ czy plankonami ${ }^{31}$ oraz proponują rozwiązania kosmologiczne, jakie sami uznają za ,zadziwiąjące" ${ }^{32}$. W koncepcji tej po rozróżnieniu między słabą a mocną definicją wszechświata przyjmuje się, iż wszechświat jako całość stanowi nieskończony ciąg wzajemnie nakładających się na siebie friedmonów, z których każdy może stanowić odrębny quasi - zamknięty układ z odmiennymi prawami ewolucji. Obserwator istniejący we friedmonie $F_{1}$ skłonny jest rozwiązywać wszystkie problemy przez odwołanie się do prawidłowości występujących $\mathrm{w}$ jego systemie. Tymczasem poza ukladem $F_{1}$ istnieją układy o innych prawach i nie można wykluczyć prawdopodobieństwa wzajemnego oddziaływania zewnętrznych układów $\mathrm{w}$ procesie ich rozwoju. Jeśli więc $\mathrm{w}$ określonym stadium ewolucji wszystkie zjawiska zachodzące $\mathrm{w}^{\mathrm{F}_{1}}$ dadzą się wytłumaczyć wewnętrznymi prawami tego systemu, to nie wynika jednak, że musiało tak być również w przeszłości.

2. Przedstawione koncepcje stwarzają radykalnie różne możliwości ujęcia problemu początku wszechświata. Obserwator umieszczony w metaukładzie opisywanym przez Błochincewa nie wiedząc o istnieniu metaprzestrzeni mógłby uważać stan osobliwy za absolutnie pierwszy stan całego wszechświata. Podobnie obserwator umieszczony wewnątrz friedmona $F_{1}$ obserwując proces ,zjawiania się" nowej materii oraz obserwując fenomeny pozbawione zjawiskowych antecedensów w obserwowanym przez niego układzie, mógłby orzekać o absolutnym początku materii i o stanach pozbawionych zjawiskowych determinant. Tymczasem obserwator $F_{2} z$ układu zewnętrznego i nadrzędnego $\mathrm{w}$ stosunku do $F_{1}$

26 The Closed Universe and Laws of Conservation of Electric Baryon and Lepton Charge, „Ann. of Phys.”, 59 (1970) 127; Zamknutyje miry sodierżaszczije. istoczniki massiwnogo wiektornogo pola, „Tieor. i Mat. Fiz.”, 16 (1973) 70; Mietrika zamknutogo mira Fridmana, wozmuszczennaja elektriczeskim zarjadom ( $k$ tieorii elektromagnitnych fridmonow), tamże, 3 (1970) 3; O minimalnych razmierach czastic $w$ obszczej tieorii otnositielnosti, tamże 13 (1972) 41; Elementarnyje czasticy maksimalno bolszich mass, ŻETF 51 (1966) 878; O ponjatii pierwomatierii, ,Wopr. Fił.”, $(1970,4) 66$; O sobstwiennoj energii czastic $w$ obszczej tieorii otnositielnosti, ,Pis'ma W ZETF", 5 (1967) 417.

${ }_{27}$ Niekotoryje fitosofskije problemy relatiwistskoj kosmologii, w: Fiłosofskije woprosy sowremiennoj fiziki, Kijew 1964, 116-148. Por. też I. S. Aleksiejew, Problema suszczestwowanija w rielatiwistskoj kosmologii, Kijew 1965, 187.

ะs Zob. Markow, Art. cyt., ,Tieor. i Mat. Fiz.”, 3 (1970) 3.

29 Markow, Art. cyt., ŻETF 51 (1966) 878.

30 Zob. J. B. Rumier, Fiziczeskoje sodierżanije 5 - optiki, ŻETF $(1960,3) 199$.

31 Zob. K. P. Stanjukowicz, ,Trudy WNII fiz. - tiechn. i radio - tiechn. izmier.", 16 (1972) 125.

32 Markow, Art. cyt., „Ann. of Phys.”, 59 (1970) 122. ,the objects (...) are wonderful in their properties (...). The physics of such objects is so original that if they are not realized, for same reason or other, in process we are dealing with above, they are worth inventing specially". 
obserwując te same procesy stwierdzałby jedynie, że skutkiem oddziaływania na siebie dwóch friedmonów część materii z zewnątrz przenika do układu $\mathrm{F}_{2}$ nie naruszając przy tym - $\mathrm{z}$ punktu widzenia obserwatora $\mathrm{F}_{2}$ - zasady zachowania energii. Materia, której zjawienie się obserwator $F_{1}$ mógł traktować jako wyłonienie się $\mathrm{z}$ nicości, dla obserwatora $F_{2}$ przechodzi jedynie z jednego układu do drugiego. Początek, który pierwszy obserwator - wprowadzając nietwórcze, choć posiadające podstawy hipotezy - mógł uważać za absolutny, jest dla drugiego obserwatora jedynie początkiem względnym, początkiem istnienia $w$ innym układzie.

W obecnym stanie badań trudno jest obiektywnie ocenić stopień prawdopodobieństwa rozwiązań, w których zarzucono ortodoksyjną zasadę kosmologiczną. Sami autorzy sygnalizowanych koncepcji nie ukrykają trudności ${ }^{33}$ i przyznają, że dokładne wypracowanie empirycznej bazy proponowanych ujęć jest jeszcze kwestią odległej przyszłości ${ }^{34}$, obecnie zaś rozwiązania te mogą być traktowane tylko jako interesujące hipotezy ${ }^{35}$. Podobnie Błochincew nie ukrywa, iż koncepcję metaprzestrzeni wprowadził jedynie po to, by uniknąc wariantu finitystycznej interpretacji osobliwości początkowej w modelach kosmologicznych. Niewątpliwym jest także fakt inspirowanią niektórych wariantów proponowanych hipotez, przez założenia materializmu dialektycznego. Widać to $\mathrm{np}$. w wypowiedziach o nieskończonej ilości układów w superprzestrzeni czy nieskończonym ciągu friedmonów. W żadnym z proponowanych ujęć nieskończoność nie jest elementem koniecznym i mógłby istnieć równiez friedmonowy wszechświat złożony ze skończonej ilości quasi - zamkniętych układów, jak i nieskończony sekwens friedmonów, który miał jako całość absolutny początek rozwoju. Dopuszczenie możliwości przyjęcia rozwiązań z nową zasadą kosmologiczną nie przesądza więc niczego odnośnie czasu istnienia wszechświata.

Interesującym jest również, że niektórzy przedstawiciele filozofii materialistycznej ustosunkowują się krytycznie do przedstawianych hipotez i podkreślają, iż ujęcia takie mają raczej fantastyczny niż naukowy charakter ${ }^{36}$. Zauważyć jednak trzeba, że granica między wytworem fantazji a hipotezami przyrodniczymi bywa często nieostra.

33 Zob. Kobuszkin, art. cyt., 126.

34 ,a consistent dynamic theory of friedmons including also the effects of the quantum fluctuation of the metric seems to be a problem of distant future", Markow, art. cyt., „Ann. of Phys.”, 59 (1970) 127.

${ }_{35}$ Tamże, 126.

36 W. W. Bażan, P. S. Dyszlewyj, W. S. Lukjaniec, Dialekticzeskij materializm $i$ problema realnosti $w$ sowremiennoj fizikie, Kijew 1974, 144 . Por. też przeciwną ocenę L. G. Antipienki, Problema fiziczeskoj realnosti, Moskwa 1973, 208. Stwierdza on: „Fridmony nie jawlajutsja plodom poeticzeskoj iantazii; zakluczenije ob ich suszczestwowanii diełajetsja na osnowanii strogich rieszenij matiematiczeskich urawnienij". 
Zwolennicy nieortodoksyjnej zasady kosmologicznej chcieliby z kolei konfirmować swoje rozwiązania przez odwoływanie się np. do teorii W. Ambarcumiana o zjawianiu się nowych gwiazd ${ }^{37}$ czy do przypuszczeń o tym, iż układy typu naszego Wszechświata stanowią analogaty kolapsarów ${ }^{38}$ i dlatego można zakładać prawdopodobieństwo istnienia zewnętrznych układów materii. Rozumowanie przez analogię trudno jednak uznać w tym przypadku za przekonywujące. Gdyby nawet przyjąc, że zamknięty wszechświat stanowi odpowiednik czarnej dziury, to nie musi się tym samym przyjmować tezy o istnieniu zewnętrznych układów materii. Tezy tej nie można jednak w sposób definitywny również odrzucić. Jeszcze przed zakwestionowaniem tradycyjnej zasady kosmologicznej możliwość istnienia układów materii ,zewnętrznych" w stosunku do obiektów opisywanych przez model Einsteina uwzględniali m. in. R. C. Tolman ${ }^{39}$, E. Schrödinger ${ }^{40}$ czy L. O. Raifeartaigh ${ }^{41}$.

3. Dla rozwiązań z zakresu filozofii przyrody mniej istotny jest problem, czy przedstawione tu nowe sformułowanie zasady kosmologicznej lepiej odzwierciedla rzeczywistość niż zakwestionowane sformułowanie tradycyjne. Istotnym jest natomiast fakt niemożności falsyfikacji nowowprowadzonej zasady. Zasada ta jest jednak de iure podatna na weryfikację, gdyż — jak pisze G. I. Naan — „to, co dziś uważa się za nieistniejące, za niemożliwe fizykalnie, jutro może należeć do sfery poznanego, okaże się istniejącym w tym lub innym sensie i będzie włączone do naszego poznania wszechświata" 42.

Jeśli uwzględni się możliwość istnienia zewnętrznych układów typu wszechświata, postulowanych w nowych sformułowaniach zasady kosmologicznej, trzeba w konsekwencji uznać problem absolutnego początku czasowego wszechświata za nierozstrzygalny. Konstruując jakikolwiek argument za absolutnym początkiem trzeba bowiem odwołać się do prawidłowości i związków zachodzących w układzie U' dostępnym do obserwacji w okresie wypracowywania argumentu za istnieniem absolutnego początku tó układu U' uważanego za cały wszechświat. Tymczasem z rozwojem badań może okazać się, że prawa obowiązujące $\mathrm{w} \mathrm{U}^{\prime}$ stanowią tylko szczególny przypadek praw zewnętrznego nieznanego uprzed-

37 Błochincew, art. cyt., 69.

38 R. K. Pathsia, The Universe as A Black Hole, „Nature”, 240 (1972) 289; The Universe Considered as Black Hole, 232 (1971) 440; J. A. Wheeler, From Relativity to Mutability, w: The Physicist's Conception of Nature, (ed. by Jagdish Mehra), Dordrecht $1973,215$.

39 Effect of Inhomogeneity on Cosmological Models, „Proc. Nat. Ac. Sc. USA”, 20 (1934) $169-176$.

40 Expanding Universe, Cambridge 1956.

41 A Static Generalisation of the Einstein Universe, "Proc. of RS”, A 245 (1958) 202.

42 Fundamientalnyje problemy sowremiennoj astronomii, w: Dialektika i sowremiennoje jestestwoznanije, Moskwa 1970, 227. 
nio systemu $U^{\prime \prime}$, moment $t_{0}^{\prime}$ oznacza jedynie początek lokalnego układu materii, zaś cała argumentacja za absolutnym początkiem, w jakiej implicite przyjęte były podstawowe założenia fizyki $\mathrm{U}^{\prime}$, nie posiada żadnej wartości, gdyż prawa te nie mogą być odnoszone do wszystkich obiektów materialnych.

Po dopuszczeniu możliwości przyjęcia nieortodoksyjnej wersji zasady kosmologicznej jedynym uzasadnionym rozwiązaniem problemu początku wszechświata jest stanowisko agnostyczne. Wyraża się ono w twierdzeniu, iż definitywne rozstrzygnięcie sporu, czy wszechświat miał początek czasowy, czy też istniał odwiecznie nie będzie możliwe nig d y.

Oczywistym jest, że niezależnie od sformułowania zasad kosmologicznych niemożliwe jest uzasadnienie tezy o odwiecznym trwaniu wszechświata. W celu zweryfikowania tej tezy należałoby odwołać sį̨ do nieskończonej ilości weryfikatorów charakteryzujących poszczególne etapy historii wszechświata składającej się z nieskończonej ilości stanów. Postulat taki jest ze zrozumiałych powodów niemożliwy do zrealizowania.

Status epistemologiczny rozwiązania konkurencyjnego jest jednak również nie lepszy. Aby dowieść tezy o absolutnym początku czasowym wszechświata trzeba by sfalsyfikować niektóre $\mathrm{z}$ wariantów nieortodoksyjnej zasady kosmologicznej. Tymczasem zasada ta $i$ postulat istnienia zewnętrznych układów materii poza granicami układu uważanego aktualnie za cały wszechświat są niefalsyfikowalne. Ponieważ de iure niemożliwe jest skonstruowanie dowodu nieistnienia układów zewnętrznych, zawsze może zachodzić obawa, iż moment, który filozofowie określonei generacji uznają za absolutny początek czasowy wszechświata okaże się z rozwojem badań tylko początkiem względnym lokalnego układu materii. Stanowisko Tomasza z Akwinu, który nie sądził, by kreacjonizm dało się pogodzić tylko z jednym z konkurencyjnych rozwiązań problemu początku czasowego wszechświata, okazuje się zarówno ostrożnym, jak i krytycznym. 


\section{NEW VERSIONS OF THE COSMOLOGICAL PRINCIPLE AND THE IMPOSSIBILITY TO SOLVE THE PROBLEM OF THE VERY BEGINNING OF THE UNIVERSE}

\section{S U M M A R Y}

In I. Kant's approach to the problem of the temporal beginning of the Universe, the possibility to prove the thesis about the absolute beginning as well as the thesis about eternal existence of the Universe was accepted. The conception presented in this paper is opposite the Kantian solution. The principal impossibility to prove a finitistic as well as an infinitistic interpretation of history of the Universe is shown in this paper. This impossibility occurs not only in the actual state of science but also will occur in its future development.

The solution of issue of the beginning depends on the cosmological principle in which the most fundamental statements concerning the Universe as a whole are assumed. In the classic version of the cosmological principle, the statistical equivalence of appropriate volumes of the homogeneous isotropic Universe was accepted. In the sixties, however, the Russian cosmologists treating classic isotropy and homogeneity assumption as an idealisation have undertaken an attempt to formulate the new cosmological principle. According to L. E. Gurevich, the new principle, stating the real existence of all theoretically possible systems of matter should be introduced instead of the classic principle about equivalence of appropriate systems in the Universe. Gurevich's conception, developed among others by M. A. Markow and A. L. Zelmanow, yields the new solutions in which possibility of existence of other systems analogous to our Universe and called "friedmons" "fundamentons" or "maxymons" is accepted. Different laws of nature, different numbers of space-time dimensions, mater properties etc. can exist, however, in these systems.

The new version of the cosmological principle is potentially verifiable, but it is not falsifiable, thus possibility that the observable Universe is but a local friedmon cannot be excluded. Consequently, with the progress of science all arguments for the absolute beginning of the Universe can turn out to be but arguments for the beginning of an local system of matter in the Universe.

In this context, on account of the principial impossibility to prove the eternal existence of the Universe, the contention concerning the very beginning of the Universe ought to be treated as substantially undecidable. 